\title{
HOW CUSTOMER INVOLVEMENT INFLUENCE LOYALTY OF CREDIT CARD HOLDERS IN INDIA
}

\author{
Matthew Tingchi Liu, University of Macau, Macao
}

\begin{abstract}
The effects of loyalty programs on consumer purchase behaviour have been extensively studied, albeit with mixed results (Meyer-Waarden, 2008; Dowling \& Uncles, 1997). A recent study by Liu (2007) on the long-term impact of loyalty programs on consumer purchase behaviour and loyalty found that loyalty programs do not affect the purchasing behaviour of heavy users, although it increased the purchase behaviour of light users. Similarly, few other studies (e.g. Lara \& De Madrariaga, 2007) have looked at the importance of rewards vis-à-vis the profile of the consumers, and. the impact of loyalty programs under different conditions of market saturation, market share, and category expandability (Liu \& Yang, 2009). Some of the key loyalty-marketing trends have been already identified and explored in detail (Capizzi \& Ferguson, 2005).
\end{abstract}

Loyalty reward point programs have been in operation in the credit card market for several decades now. Liu and Yang (2009) reported that in the credit card industry, half of general-purpose credit cards offer a reward program. Mägi (2003) notes that despite the customer loyalty reward programs in this industry reaching a stage maturity, the multiplicity of the loyalty program memberships may also allow having fair judgement to individual programs. Reflecting this concern, academic research also has expressed doubts about the value of such loyalty programs to firms (e.g., Dowling \& Uncles, 1997; Shugan, 2005). Several scholars have also suggested that delayed rewards in a loyalty program have a significantly different impact on customer loyalty (e.g., Leenheer \& Bijmolt, 2008).

According to Bolton, Kannan, and Bramlett (2000), credit card users belonging to any reward programs spend more using their cards than non-members, but were not more likely to retain their accounts over time, i.e., the programs increase usage but do not appear to build loyalty. There are essentially three types of rewards programs for credit card users: point-based, cash back, and airline miles, with some cards offering combinations of these. The current research focuses on point-based programs. Benefits of reward points from using a credit card are dependent on the program selected by the customer, but can include free flights, free accommodation, electronic equipment, vouchers and gift certificates to major retailers, magazine subscriptions, passes to major theme parks, etc. Despite its higher returns, consumers find the redemption procedure of pointbased rewards to be too much trouble - instead preferring the simplicity of automatic cash back credit (Liu, 2009). For example, unlike cash back cards, point-based reward cards usually require card holders to keep track of their points and submit requests when they qualify for point redemption. Point-based rewards usually expire if not redeemed within a fixed time period. Further, the rate of return ("redemption ratio") of some point-based reward programs varies considerably depending on what is redeemed; retailer vouchers may carry a higher return than gasoline, for example. Compared with the complexity of point-based reward programs, and the implicit need for customers to manage their accounts, customers with cash back credit cards automatically get a portion of their purchases back as statement credits or a cash back checks after a certain period of time. Besides, Van et al. (2004) and O'Brien and Jones (1995) have found that the manner in which the structure of the point reward system also impacts redemption behaviour by consumers.

However, past research has dealt with issues related to characteristics of rewards and their impact, mostly in the developed countries. However, there is limited empirical research in emerging markets that explores whether credit card reward point programs enhance customer loyalty. Moreover, there is also little understanding of the degree to which credit card users actually value reward point programs in emerging markets such as India. The early 1990s witnessed a quantum growth in the Indian credit card industry. Not surprisingly, credit cards have found greater acceptance and usage in major metropolitan cities of India. Increased competition has helped accelerate growth of the Indian credit card market, one result of which is more options for Indian customers. Collectively, credit card companies have also helped increase the overall acceptability of plastic, and hence usage. In 2009, the total number of credit cards in India was estimated to be 24.4 millions (Schulz, 2009) with 14 major banks and financial institutions providing credit card products and services. With increasing numbers of credit card issuers and increasing competition, several Indian banks are entering into joint ventures with international brands such as MasterCard and Visa (Mukherjee, 2006). According to Visa, the largest credit card type in India, India is one of the fastest growing markets worldwide, and it is estimated to be the fourth largest market in the Asia Pacific region (The Economic Times, 2006). In such growing and vibrant credit card market in India, it is important to understand if loyalty programs offered by the credit card companies actually work, and to what extent. This paper studies the impact of credit card loyalty reward point programs on the purchasing behaviour of Indian credit card users. A total of over 100 valid responses were collected using an online survey of Indian credit card users.

\section{REFERENCE AVALIABLE UPON REQUEST}

